\title{
Ensaio sobre as relações entre Educação, Ciência e Sociedade a partir da perspectiva do desenvolvimento humano
}

DOI 10.26512/lc.v24i0.19851

\author{
Juliano Camillo \\ Universidade Federal de Santa Catarina \\ Departamento de Metodologia de Ensino \\ juliano.camillo@ufsc.br \\ Cristiano Rodrigues de Mattos \\ Universidade de São Paulo \\ Departamento de Física Experimental \\ mattos@if.usp.br
}

\section{Resumo}

A noção de "relevância da ciência" é nosso objeto no presente ensaio. Fazemos a proposição de que a partir dela pode-se compreender as particulares conceitualizações acerca das interconexões entre educação, ciência e sociedade. Partindo de tal princípio, ensaiamos com quatro formas de relevância: "Ciência, consolidação institucional e domínio da natureza"; "Ciência e participação"; "Ciência, uma forma a mais de conhecer o mundo, porém perigosa"; e "Ciência e Desenvolvimento Humano". As três primeiras, apesar de relativamente autônomas, constituem-se de um prelúdio para quarta, na medida em que explicitam algumas das mais difundidas concepções (e seus problemas associados) acerca das relações entre educação, ciência e sociedade. Na última parte, a questão da relação entre ciência e desenvolvimento humano é tomada a partir de uma perspectiva ontológica.

Palavras-Chave: Desenvolvimento Humano, Ontologia, Relevância da Ciência 


\section{Resumen}

La noción de "relevancia de la ciencia" es nuestro objeto en el presente ensayo. Proponemos que a partir de ella se pueden comprender las particulares conceptualizaciones acerca de las interconexiones entre educación, ciencia y sociedad. Partiendo de este principio, realizamos un ensayo con cuatro formas de relevancia: "Ciencia, consolidación institucional y dominio de la naturaleza"; "Ciencia y participación"; "Ciencia, una forma más de conocer el mundo, sin embargo peligrosa"; y "Ciencia y desarrollo humano". Las tres primeras, a pesar de ser relativamente autónomas, constituyen un preludio para la cuarta, en la medida en que explicitan algunas de las más difundidas concepciones (y los problemas a ellas asociados) acerca de las relaciones entre educación, ciencia y sociedad. En la última parte, el asunto de la relación entre ciencia y desarrollo humano es abordado a partir de una perspectiva ontológica.

Palabras claves: Desarrollo Humano, Ontología, Relevancia de la Ciencia.

\section{Abstract}

"Relevance of science" is our object in this essay. We propose that from it we can understand the conceptualizations about interconnections between Education, Science, and Society. From this principle, we discuss four forms of relevance: "Science, institutional consolidation and mastery of nature"; "Science and participation"; "Science, one more way to know the world, but dangerous"; and "Science and Human Development". The first three, despite being relatively autonomous, constitute a prelude to the fourth, insofar as they explain some of the most widespread conceptions (and their associated problems) about the relations between Education, Science, and Society. In the last part, the issue around the relationship between Science and Human Development is taken from an ontological perspective.

Keywords: Human Development, Ontology, Relevance of Science 


\section{Résumé}

La notion de "pertinence de la science" est notre objet dans cet essai. Nous faisons la proposition que l'on peut comprendre les conceptualisations particulières sur les interconnexions entre l'éducation, la science et la société. Partant de ce principe, nous répétons avec quatre formes de pertinence: "Science, consolidation institutionnelle et maitrise de la nature"; "Science et participation"; "La science, un moyen de mieux connaître le monde, mais dangereux"; et "Science et développement humain". Les trois premiers, bien que relativement autonome, constituent un prélude à la quatrième, dans la mesure où expliquer certaines des conceptions les plus répandues (et ses problèmes associés) sur la relation entre l'éducation, la science et la société. Dans la dernière partie, la question de la relation entre la science et le développement humain est prise dans une perspective ontologique.

Mots clés: Développement humain, ontologie, pertinence de la science

\section{Introdução}

"Ele foi o melhor professor de Física que eu tive na escola. Ele sabia tudo. Era a pessoa mais inteligente, apesar de que eu não entendia nada do que ele dizia".

Tornou-se lugar-comum a afirmação de que a Ciência goza de grande prestígio na sociedade contemporânea. Paradoxalmente, tal prestígio sobrevive apesar do crescente desinteresse por carreiras científicas (Gouw, Mota, \& Bizzo, 2016), consideradas socialmente relevantes porém desestimulantes para serem seguidas por muitos indivíduos; sobrevive, também, apesar do paulatino (re)surgimento de movimentos anticiência (Hansson, 2017), como o terraplanista e o antivacina, que visam, entre outras coisas, expressar o suposto caráter exclusivamente enganador da ciência moderna; e, ainda, apesar das sempre presentes concepções conservadoras (Bagdonas \& Azevedo, 2017), que advogam por uma ciência exclusivamente pragmática, instrumentalista e, sobretudo, neutra, a partir da qual não se teria (e não se almejaria) qualquer possibilidade de produzir conhecimento verdadeiro acerca da realidade e de proporcionar uma profunda reformulação de visões de mundo ao longo da história.

O suposto prestígio da ciência não pode, no entanto, ser tomado de modo acrítico, sobretudo num momento em que conhecimentos de/sobre a ciência são proclamados como necessários para que os indivíduos possam participar de uma sociedade cada vez 
mais influenciada pela Ciência e Tecnologia. Espera-se que, para além da compreensão do mundo natural, a Educação em Ciências promova indivíduos "alfabetizados cientificamente", que ao se apropriarem dos conhecimentos científicos desenvolvam pensamento crítico e sejam capazes de participar das tomadas de decisões em situações nas quais conteúdos científicos estejam envolvidos, buscando a construção da cidadania (DeBoer, 2000; Osborne, 2007, 2010). Dentro desta perspectiva, toma lugar a difundida concepção de que a educação deveria cumprir seu papel de mediadora entre a ciência e a sociedade, sendo capaz de efetivamente traduzir (transpor, transferir) os conhecimentos produzidos pelos cientistas (autoridades, especialistas) para o conjunto de indivíduos que não necessariamente estão familiarizados com a produção científica (leigos, mas potenciais partícipes de decisões democráticas). Mais recententemente, afirma-se que a educação em ciências deveria "promover condições para que os alunos fossem inseridos em mais uma cultura, a científica" (Sasseron \& Carvalho, 2011), possuidora de linguagens, práticas, estruturas próprias, distintas daquelas presentes na vida cotidiana.

Além disso, tem havido nas últimas décadas esforços no sentido de compreender a ciência a partir das suas dimensões sociológica, histórica, antropológica etc., buscando, sobretudo, superar a concepção da atividade científica como neutra ou apartada dos seus meios concretos de sua produção, isto é, uma tentativa de caracterizar a ciência como uma construção humana. No campo da Educação em Ciências tais esforços estão intimamente relacionados àquelas perspectivas de enculturação científica, em especial no que diz respeito à explicitação das idiossincrasias da comunidade científica (Sasseron, 2015; Sasseron \& Carvalho, 2011). Tais esforços também podem ser identificados nos autores que defendem a introdução de aspectos de história e filosofia da ciência no ensino, a fim de contribuir para uma imagem mais fiel acerca da produção científica (Pérez, Montoro, Alís, Cachapuz, \& Praia, 2001; Praia, GilPérez, \& Vilches, 2007), e, ainda, naqueles que buscam compreender as relações entre Ciência, Tecnologia e Sociedade (movimento CTS) explicitando e analisando as condições de produção da ciência e da tecnologia e as funções sociais por elas desempenhadas (Auler \& Delizoicov, 2015). Nesse sentido, cada vez mais a Educação em Ciências tem se consolidado também como um campo de pesquisa, produzindo um lastro considerável de reflexões acerca das atividades educacionais, da natureza do conhecimento científico e da relevância da Educação em Ciências, inclusive para uma formação humanística (Aikenhead, 2006; Donnelly, 2002), que visa a superação de uma educação puramente propedêutica e para além da exploração dos conceitos básicos de uma área específica das Ciências.

Considerando a complexidade do fenômeno da Educação em Ciências, pesquisadores têm apontado a necessidade do desenvolvimento de uma Filosofia da Educação em Ciências (Camillo, 2015; Schulz, 2009), considerando que há, no interior deste campo, a "ausência de uma teoria geral que unifique e dê coerência a conceitos, fenômenos e circunstâncias relativas ao ensino, à aprendizagem e à formação" (Cachapuz, Praia 
\& Jorge, 2004, p. 634), de modo que seu objeto específico de investigação possa ser apreendido de maneira concreta (Rodrigues, Camillo \& Mattos, 2014). É dentro desta perspectiva que buscamos aqui trazer contribuições teórico-metodológicas para o enfrentamento de questões contemporâneas acerca das relações entre ciência, educação e sociedade, visando superar tratamentos reducionistas e que absolutizam a autonomia de cada uma das atividades em questão (de modo a ter que ser analisada em si mesma).

Diante disto, a "relevância da ciência" é nosso objeto no presente ensaio¹. Não significa que propomo-nos fazer um exaustivo levantamento acerca dos diferentes sentidos atribuídos à ciência e dos motivos pelos quais a Ciência e a Educação em Ciências são relevantes para a sociedade contemporânea. Tampouco significa que buscamos fazer uma profunda análise histórica que explicite as condições de emergência da Ciência Moderna e os motivos pelos quais ela goza de prestígio na contemporaneidade. Considerando os limites do presente trabalho, tais sentidos, por ora, são apresentados na medida em que explicitam nosso argumento central: a "relevância da ciência", por seu caráter contraditório, nos permite reconstruir, no plano teórico, as profundas interconexões entre educação, ciência e sociedade. Ou seja, na medida em que são apreendidas teoricamente as determinações de uma forma particular de como a ciência é considerada relevante, capta-se necessariamente as formas pelas quais a atividade científica, os processos educacionais e o funcionamento da sociedade são particularmente concebidos, uma vez que, explicita também as visões de futuro presentes em tais concepções. Nesse sentido, uma particular forma de conceber a relevância da ciência é a síntese das concepções particulares de educação, ciência e sociedade em questão.

O tratamento de forma unitária das relações entre educação, ciência e sociedade, abre, sob nosso ponto de vista, possibilidades de superação tanto das tradicionais narrativas únicas e esvaziantes que tomam a atividade científica como positivista, objetiva e neutra, quanto das críticas à ciência positivista, objetiva, neutra que acabam por tirar da ciência a possibilidade de produzir conhecimento verdadeiro sobre a realidade. Nosso ensaio acerca das relações entre educação, ciência e sociedade, por meio da célula contraditória da "relevância da ciência", dar-se-á a partir da consideração que as atividades são o tecido da realidade humana e que a ciência tem sua origem nos complexos processos de transformação da realidade operados pelos seres humanos. Nesta perspectiva, os seres humanos vêm a conhecer a si mesmos e o mundo e, em última instância, tornar-se humanos por meio do processo de transformar o mundo de maneira colaborativa, considerando seus propósitos e interesses, vinculados

$1 \mathrm{E}$ aqui, em certa medida, nos valeremos da perspectiva de Adorno (2003, p. 180) ao conduzirmos nosso ensaio (ou quatro pequenos ensaios-sessões): "É inerente à forma do ensaio a sua própria relativização: ele precisa comporse de tal modo como se, a todo momento, pudesse interromper-se. Ele pensa aos solavancos e aos pedaços, assim como a realidade é descontinua, encontra sua unidade através de rupturas e não à medida que as escamoteia. $\mathrm{A}$ unanimidade da ordem lógica engana quanto à essência antagônica daquilo que ela recobre. A descontinuidade é essencial ao ensaio, seu assunto é sempre um conflito suspenso". 
necessariamente tanto à herança do passado quanto à visão que possuem acerca do futuro. Não existe, assim, dentro desta perspectiva, rupturas ou dualismos entre agir, ser e conhecer. Todas as atividades humanas estão relacionadas com algum grau de transformação da realidade e estão profundamente imbuídas de ideologias e valores (Stetsenko, 2008).

\section{Relevância: Ciência, consolidação institucional e domínio da natureza}

A presença das disciplinas científicas no currículo tem uma história relativamente curta. Segundo Aikenhead (2009), o primeiro curso de ciência escolar foi criado em 1867, na Inglaterra, por uma comissão da British Association for the Advancement of Science e a introdução das disciplinas científicas nos currículos dos Estados Unidos da América e da Europa se deu em parte pelo apelo dos próprios cientistas, em um momento no qual as humanidades estavam bem consolidadas no currículo escolar e consideradas promotoras dos resultados educacionais mais valiosos e nobres (DeBoer, 1991). Esperava-se, então, que a aprendizagem da ciência fosse capaz de promover um treinamento intelectual de alto nível, não pautado na lógica dedutiva - presente na maior parte da educação formal, mas na lógica indutiva, presente no processo de observação da natureza e delineamento de conclusões. Tal lógica seria aprendida pelos estudantes em investigações no laboratório didático e conduziriam a uma atitude de independência, fundamental para se evitar excessos de uma possível autoridade arbitrária e assim efetivamente contribuir para uma sociedade mais democrática.

É nesse momento que a Ciência (antes Filosofia Natural) passa por um processo de institucionalização e profissionalização, em sintonia com o ideal da nascente burguesia, que procurava estabelecer e expandir o domínio dos seres humanos sobre a natureza, explorando-a para fins privados. Na luta por consolidar-se institucionalmente, a ciência buscava trazer uma nova forma de autoridade e conhecimento, baseados na observação e na racionalidade, na experimentação e na matematização. No entanto, de maneira a não criar conflitos com a nova ordem religiosa que se estabelecia, os filósofos naturais dedicar-se-iam a produzir conhecimento sobre o mundo objetivo natural, com afirmações que não contradissessem as escrituras sagradas e sem opinar sobre religião, política e moral. A ciência ganha parte da forma como a conhecemos hoje e a ideia de que conhecimento é poder passa a consolidar-se.

É no final do século XVIII, no entanto, que o ideal de dominação da natureza consolidase a partir da revolução industrial, sobretudo no que diz respeito ao poder e ao controle sobre a produtividade humana. Opera-se uma transformação radical nos 
modos de produção, fazendo com que a capacidade produtiva humana chegasse a níveis inimagináveis, e efetiva-se uma aparente divisão entre uma ciência pura e a sua aplicação, que ficou tradicionalmente conhecida como tecnologia (Aikenhead, 1994)?]. A partir desta separação, muitos dos filósofos começam a autodenominar-se cientistas e passam a isolar-se das aplicações práticas (nas universidades, por exemplo) e a dedicar-se à curiosidade e à produção de conhecimento pelo propósito do próprio conhecimento, uma vez que aplicações práticas eram consideradas inferiores, de menor qualidade ou mesmo vulgares. Passa a existir, também, o estabelecimento de rigorosos padrões para o acesso ao seleto grupo de pessoas que poderiam tornar-se cientistas. A ciência, então, até o final do século XIX, havia se tornado uma profissão. Física, Química, Biologia e Geologia tinham sua autonomia administrativa dentro das universidades (Aikenhead, 1994), possuindo, além disso, educação, literatura e sociedade próprias(Bernal, 1965).

Um conjunto de ideias sobre a ciência que emerge no final do século XIX e início do século XXé nomeado por Auler (2011) como Modelo Tecnocrata/Cientificista. Neste modelo busca-se na ciência "um substituto para a política, movida por ideologias, conflitos, irracionalidades, incertezas, subjetividade, pela emoção/paixão. A ciência, na visão cientificista, com sua suposta objetividade, neutralidade e racionalidade, finalmente nos trouxe certezas para a tomada de decisões" (p. 73).

Como argumenta Auler (2002), no interior deste modelo estabelecem-se mitos acerca da relação Ciência, Tecnologia e Sociedade. O primeiro deles é o mito do Mito do Determinismo Tecnológico, segundo o qual a mudança social é causada pela mudança tecnológica, que define os limites do que a sociedade é capaz de fazer. Ainda, segundo este ponto de vista, a tecnologia é uma instância autônoma que não sofre influências da sociedade. Um segundo mito é o da Ciência Salvacionista, segundo o qual os problemas sociais serão resolvidos, em algum momento, pela ciência e tecnologia. Nesta perspectiva, a ciência e tecnologia levam necessariamente ao desenvolvimento econômico e, por conseguinte, ao bem-estar da humanidade. $O$ terceiro mito é o da Superioridade da Ciência, segundo o qual seria possível neutralizar a influência ideológica na pesquisa científica. Os problemas humanos podem ter uma solução ótima, que é alcançada unicamente por meio dos conhecimentos científicos supostamente neutros, ou seja, não há influência de nenhum outro elemento que não o conhecimento científico (Auler, 2002, 2011).

Permeada por tais concepções é que as disciplinas científicas passam a ser introduzidas no currículo da escola básica no século XIX. E tal introdução se dá pela reprodução do modelo universitário e que carrega consigo os pressupostos que lhes deram origem: valorização do conhecimento pelo próprio conhecimento, evitando aplicações práticas e ignorando quaisquer valores não-científicos e questões de relevância social (Aikenhead, 1994). Neste período, as disciplinas escolares focavam, então, em puras abstrações, com o objetivo de demonstrar a unidade estética das disciplinas científicas, 
concebendo a ciência como um processo de investigação puramente racional e objetivo rumo ao conhecimento absoluto (ibidem).

A ciência escolar desde sua origem sofre com o dilema entre uma educação para os que se tornarão cientistas (que serão produtores de ciência) e para aqueles que não seguirão na carreira científica (que tornar-se-ão consumidores desta mesma ciência em suas vidas cotidianas) ${ }^{2}$. Para o futuro cientista, a educação básica tem como objetivo apresentar um conjunto de princípios sobre os quais a ciência, na qual futuramente trabalhará, fundamenta-se (a ciência na sua forma canônica), de modo a fazê-los agir e pensar como cientistas. Partindo do pressuposto que o conhecimento científico é cumulativo, cada geração tem mais coisas para aprender que a geração que a precedeu. Daí muitos cursos de Ciências na Educação Básica estarem centrados na simples memorização de fatos ou na apresentação enciclopédica de informações sobre diferentes áreas científicas, cada vez mais especializadas, impedindo que os alunos estabeleçam um sentido de totalidade diante destes dados, considerando a sempre crescente quantidade de conhecimentos que são acumulados (Osborne, 2007).

No Brasil, a tradição de um ensino humanístico-literário, no final do século XIX, não favoreceu a entrada das disciplinas científicas nos currículos escolares. A disciplina de Física, por exemplo, apesar de incluída no rol de disciplinas escolares, não tinha relevância para o acesso ao ensino superior. Somente no começo do século XX, a passa a ser justificada e exigida no ensino secundário, em cidades como São Paulo e Rio de Janeiro, devido as exigências dos cursos superiores de engenharia e medicina que pretendiam desocupar sua grade curricular dos conteúdos típicos da física básica. Ou seja, a Física passa a ser obrigatória nos cursos secundários porque determinados cursos superiores necessitavam que os alunos entrassem na universidade já com alguma iniciação em disciplinas científicas (Nicioli \& Cri, 2012).

\section{Relevância: Ciência e participação}

A alfabetização científica (ou enculturação científica), apesar de constituir-se nos últimos anos do motor de diversas reformas curriculares ao redor do mundo, tem sido considerada problemática. Para muitos, ela é mais um slogan que uma proposta educacional passível de ser efetivada. Ela contém problemas na sua delimitação, gerando confusão e uma variedade muito grande de interpretações (DeBoer, 2000;

2 Dupla tarefa que continua de maneira explícita até os dias de hoje: "A comunidade da educação em ciências continua a negociar uma agenda dupla; centra-se simultaneamente na preparação dos cidadãos habilitados a envolverem-se com a ciência como uma conquista humana e um empreendimento multi-dimensional que toca em quase todos os aspectos de suas vidas, enquanto apoia estudantes interessados, e capazes de, prosseguir os estudos científicos acadêmicos e carreiras científicas" (Abd-El-Khalick; Zeidler, 2015, p. 264). 
Fensham, 2015; Laugksch, 2000; Shamos, 1995). São criticados desde os modos de pelos quais democracia e participação são tradicionalmente conceitualizados (Levinson, 2010), passando pelas compreensões acerca da aprendizagem e da individualidade humana (Camillo, 2015), até os processos de medição do nível de alfabetização científica em níveis globais visando a formulação de políticas públicas (Sjøberg, 2017).

A própria noção de utilidade do conhecimento científico é problemática. Gough et al. (2009), por exemplo, apontam que os jovens, mesmo sabendo dos riscos do tabagismo, justificam seu ato de fumar defendendo que atualmente muitas coisas além do cigarro fazem mal a saúde. Minimizam, assim, os possíveis malefícios trazidos pelo cigarro ao passo que enfatizam alguns supostos benefícios, como o fato de que o cigarro pode efetivamente ser usado para aliviar o stress. Além disso, muitos jovens apontam que o ato de fumar está associado à juventude, como uma construção social típica desta faixa etária e que o ato de fumar cessará com a chegada da idade adulta. Neste sentido, na perspectiva dos jovens, a escolha por fumar é claramente racional e situada e não relacionada com vícios. Assim, o critério supostamente racional transcende o conhecimento científico acerca dos malefícios acerca do cigarro, visto que a própria racionalidade na visão dos jovens fumantes passa a ser distinta daquela que se espera ao conceber o papel de elemento crítico ao conhecimento científico na tomada de decisão.

Por outro lado, Yang e Anderson (2003), apoiados em uma perspectiva de promover a alfabetização científica e aprofundar as relações CTS, mostram que os estudantes do ensino médio podem facilmente ser afetados por fatores emocionais quando estão avaliando evidências científicas. Os diferentes modos de raciocínio apresentados pelos diferentes grupos estão associados às suas crenças, valores e emoções durante o processo de resolução de problemas. Segundo os autores, os estudantes "cientificamente orientados" parecem ter grande confiança na objetividade da ciência enquanto os estudantes "socialmente orientados" tendem a justificar suas respostas verbalizando suas emoções e compartilhando suas experiências para justificar suas respostas.

No que diz respeito a utilização da Ciência na vida cotidiana, Yang (2004) argumenta que os alunos, mesmo os jovens adultos, têm exibido incapacidade de usar o raciocínio científico em questões sociais no contexto de vida, apesar de apresentarem tais habilidades em situações específicas nas quais o seu domínio é obrigatório. Isto é um indício da dificuldade de transferência das habilidades de raciocínio a diferentes contextos. Além disso, muitas vezes, parece haver conflitos entre o raciocínio científico na escola e em contextos sociais. Nielsen (2012) aponta que o conhecimento científico muitas vezes pode, por si só, não justificar uma decisão carregada de valor, decisões sobre questões sociais tendem a ser simplesmente decisões de valor. 
Jenkins (1999) aponta, ainda, que no mundo cotidiano a ciência "emerge não como conhecimento coerente, objetivo e não problemático, mas como incerto, controverso e muitas vezes incapaz de responder a muitas questões importantes com o necessário grau de confiança" (p. 704). Aponta, ainda, que em alguns casos o conhecimento científico é deixado de lado e até mesmo considerado irrelevante diante do problema em questão, enquanto o pensamento cotidiano, pela sua própria natureza, acaba por ser bem adaptado para a tomada de decisões em um mundo "marcado pela incerteza, contingência e de adaptação a uma gama fatores não controlados" (p. 704).

No que diz respeito à participação democrática, Osborne (2010, p. 53), por exemplo, chama de "argumento democrático" aquele que defende a educação em ciências na escola básica em termos da participação na sociedade, visto que uma democracia saudável necessita que todos os seus cidadãos, ou que pelo menos a maioria deles, participem das decisões nas quais a ciência está presente. Segundo ele, isso só é possível se os indivíduos tiverem conhecimentos básicos da ciência que subjaz tais questões. O autor assume, então, apoiado em Millar (Millar, 2006), a posição de que os cidadãos não são construtores do conhecimento, mas devem constituir-se consumidores críticos deste conhecimento, uma vez que a produção do conhecimento científico novo é uma tarefa no qual uma minoria da sociedade participa.

É importante destacar que, à maneira como acontece com outros termos, democracia é polissêmico, assumindo diferentes significados para diferentes pessoas dependendo das fundamentações adotadas. Coutinho (Coutinho, 2002), aponta que "[...] o fato de que todos hoje se digam democratas não significa que acreditem efetivamente na democracia, mas sim que se generalizou o reconhecimento que a democracia é uma virtude" (p. 12). Ele também aponta que aquilo que corriqueiramente se chama de democracia não é o que a história da humanidade e também o pensamento político entendem por tal conceito. É preciso então, segundo o mesmo autor, cautela ao utilizar o termo democracia, visto que em determinados momentos o liberalismo é contra a democracia, apresentando-se como uma alternativa ao modelo democrático, enquanto no século XX, sobretudo a partir dos anos de 1930, "o liberalismo assume a democracia e passa a defendê-la, mas reduzindo-a e minimizando-a, empobrecendo suas determinações, concebendo-a de modo claramente redutivo" (p.11).

Tal empobrecimento, em particular na Educação em Ciências, é observado no recorrente e superficial discurso de que a educação deve fornecer instrumentos para que os supostos cidadãos possam participar da sociedade contemporânea sem, no entanto, problematizar o significado e as consequências concretas de assumir um ou outro posicionamento diante de um modelo político. Além disso, Cassab (2008)reconhece, junto com Auler e Delizoicov (2001), o problema de se construir um modelo democrático pautado numa concepção tecnocrática de ciência. Apesar de reconhecer os efeitos nocivos do desenvolvimento científico "seja à custa da exploração desenfreada dos recursos naturais (gerando impactos sócio-ambientais 
antes nunca imaginados), seja da destruição ou apropriação de outros sistemas de conhecimento [...]" (Cassab, 2008, p. 4), a autora enfatiza o papel que as ciências desempenham na construção de uma sociedade democrática, dada a importância que o conhecimento científico representa para a sociedade contemporânea, tomando como falsa a concepção da "impossibilidade do cidadão comum em compreender os conhecimentos científicos necessários à sua participação social, em vista de sua complexidade e extensão" (Cassab, 2008, p. 5). Ela argumenta que a posse de conhecimentos científicos específicos, por parte dos especialistas, por exemplo, não garantiria necessariamente uma tomada de posição que seja relevante à maioria da população.

Autores como Fensham (2015) e Shamos (1995) consideram irrealista a possibilidade de uma sociedade tornar-se cientificamente alfabetizada de maneira a participar das tomadas de decisão em questões sociocientíficas, como as relacionadas aos desenvolvimentos em biotecnologia ou aquecimento global, considerando a complexidade dos conceitos científicos que estão imbricados nestas problemáticas. Como alternativa ao modelo de alfabetização científica, Shamos (1995) propõe o conceito de Scientific Awareness (consciência científica), que implica promover um ensino de ciência que desenvolva a apreciação e a consciência sobre o empreendimento científico, que esteja em torno do tema da tecnologia e da sua relevância para a vida dos indivíduos no que diz respeito a sua segurança e saúde. Por fim, um ensino que promova alfabetização social (cívica), de maneira que se possa policiar como os peritos científicos atuam em questões técnicas, visto que são eles que podem resolver tais questões.

De maneira bastante profunda, a expectativa de que cada indivíduo por si só seja capaz de apropriar-se de uma série de conhecimentos científicos para então poder atuar na coletividade, nada mais é do que a expressão da concepção individualista de ser humano, a partir da qual a coletividade humana não seria nada além de um apanhado de indivíduos (regulados por um conjunto de normas de convivência, circulação etc), desenvolvendo-se de maneira autônoma em relação ao conjunto da humanidade. Dentro desta perspectiva, não haveria possibilidades reais de uma transformação radical da sociedade, de modo a vislumbrar outros sistemas econômicos/políticos. Assim sendo, diante da impossibilidade de superação das perspectivas individualistas de ser humano, restaria somente a necessidade de promover melhorias no plano individual esperando-se que tais melhorais sejam, por conseguinte, transferidas para o conjunto da sociedade. 


\section{Relevância: Ciência, uma forma a mais de conhecer o mundo, porém perigosa}

As reivindicações por uma outra Educação em Ciências ao longo das últimas décadas trazem consigo, apesar de não estarem necessariamente associadas, algumas reivindicações por outras formas de fazer/pensar a Ciência, considerando de modo mais efetivo as reais necessidades dos seres humanos e buscando superar os malefícios trazidos pelo desenvolvimento desenfreado, muitas vezes associados ao desenvolvimento científico e tecnológico. Do ponto de vista que nos interessa aqui desenvolver, há duas tendências predominantes dentro desse movimento (de caracterização da ciência como construção humana), que merecem maior atenção, ainda que tal atenção seja limitada considerando os limites deste ensaio.

A primeira tendência é aquela que, ao buscar superar as concepções empiristas, indutivistas e ateóricas, segundo as quais a ciência é vista como um projeto neutro de observação da realidade, procura mostrar o modo pelo qual a produção do conhecimento científico é influenciada por fatores sociais. Dentro desta tendência estão, por exemplo, os trabalhos que inseridos na perspectiva de Robert Merton, considerado por muitos como o fundador da sociologia da ciência. De acordo com Merton (1970), é possível identificar um ethos da ciência, que é orientador das práticas do cientista. A ciência é vista como uma instituição que exerce influência e é influenciada por outras instituições políticas e econômicas. No entanto, apesar de tais influências, o empreendimento científico seria essencialmente autônomo em relação a estes fatores que lhe são externos. Tal autonomia seria, por suposto, aquilo que permite a ciência produzir conhecimento verdadeiro (Shinn \& Ragouet, 2008).

A partir desta perspectiva a ciência poderia ser vista como uma construção humana porque, em primeiro lugar, é conduzida por seres humanos. Segundo, porque sobre a atividade científica poderia haver influências sociais que modificariam, por exemplo, as agendas de investigação, levando em conta interesses políticos e/ou econômicos. Ou seja, a atividade científica acontece a partir da junção de uma série de fatores: econômicos, políticos, sociais etc...Porém, esta primeira tendência esquiva-se do tratamento do cerne da produção científica ou dos métodos da Ciência, de modo que, em grande medida, a Ciência continua sendo concebida a partir de pressupostos positivistas. Isso significaria, que os fatores sociais influenciariam somente quando e o que a Ciência produziria, mas não como tais conhecimentos são produzidos.

A segunda tendência a qual nos referimos é aquela que procura criticar as concepções positivistas e neutras da ciência caracterizando-a como um conjunto de acordos intersubjetivos, como negociações entre os membros da comunidade científica. Exemplo dessa tendência pode ser identificada em: 
Portanto, eis a minha ideia: a objetividade é o resultado de um processo crítico desenvolvido por uma comunidade/sociedade científica num jogo em que ela assume plenamente as regras. Ela é produzida por um consenso, porque qualquer um que reflita sobre a objetividade pode dizer: "O que nos faz ver que alguma coisa é objetiva?" Bom! Na verdade, é um consenso de pesquisadores. Temos confiança nesse consenso de pesquisadores e, como diz Popper, a objetividade dos enunciados científicos reside no fato de eles poderem ser intersubjetivamente submetidos a testes. (Morin, 2005, p. 42)

Tal concepção compreende, em certa medida, a concepção pós-moderna. "Em certa medida" porque, como aponta Eagleton (1998, p. 7), "o pós-modernismo constitui um fenômeno tão híbrido, que qualquer afirmação sobre um aspecto dele quase com certeza não se aplicará a outro". Aqui, seremos cuidadosos ao evocar o conceito de

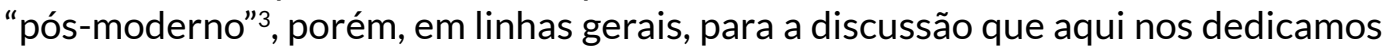
acerca da ciência, a síntese de Eagleton (1998, p. 7) parece-nos oportuna:

Pós-modernidade é uma linha de pensamento que questiona as noções clássicas de verdade, razão, identidade e objetividade, a ideia de progresso ou emancipação universal, os sistemas únicos, as grandes narrativas ou os fundamentos definitivos de explicação. Contrariando essas normas do iluminismo, vê o mundo como contingente, gratuito, diverso, instável, imprevisível, um conjunto de culturas ou interpretações desunificadas gerando um certo grau de ceticismo em relação à objetividade da verdade, da história e das normas, em relação às idiossincrasias e a coerência de identidades.

É recorrente o discurso segundo o qual a humanidade encontra-se em um novo período histórico ${ }^{4}$ e de que o projeto moderno e os paradigmas da modernidade estão colapsados, ou seja, que a promessa moderna de um conhecimento que permitiria um controle racional da natureza e da sociedade e as promessas acerca das possibilidades emancipadoras da razão ou não têm mais validade ou eram falsas desde a sua origem - dois grupos de pensadores, segundo a caracterização de Santos (1997) -, dadas as catástrofes ambientais e os problemas sociais que hoje enfrentamos. Aqueles que defendem essa posição utilizam-se de exemplos nas artes, na arquitetura, na literatura, no mundo do trabalho, na economia e na própria ciência para sustentar-se dentro desta perspectiva.

3 Neste sentido, quando nos referirmos ao pós-modernismo, buscaremos explicitar o conjunto de ideias ou pressupostos aos quais estamos nos referindo, a fim de que a discussão se desenvolva em torno das concepções ao invés do seu pertencimento ou não ao referido movimento. Primeiro, porque isto nos introduziria um problema maior que é o da caracterização de um campo tão heterogêneo e multiforme por meio de categorias consistentes e de um levantamento bibliográfico muito maior. Segundo, porque após a caracterização do campo pós-moderno, teríamos que localizar as concepções que aqui estamos criticando dentro deste campo, mapeando aproximações ou distanciamento, de autores, como Kuhn, Morin, Feyerabend, o que exigira um trabalho à parte.

4 "A época em que vivemos deve ser considerada uma época de transição entre o paradigma da ciência moderna e um novo paradigma, de cuja emergência se vão acumulando os sinais, e a que, à falta de melhor designação, chamo ciência pós-moderna" (Santos, n.d., p. 9). 
Netto (2000), ao analisar a distinção em dois grupos feita por Santos (Santos, 1997), aponta que, para os pensadores para os quais os projetos da Modernidade eram falaciosos desde o princípio, a História chegou ao seu fim. Isto significaria que não há nenhuma alternativa para a sociedade contemporânea e, portanto, as possibilidades de transformação social radical não estão postas. Estes pensadores, nos termos de Santos, são integrantes do "pós-modernismo de celebração" (Santos, 1997, p. 35). Para aqueles aos quais o projeto Moderno não era falacioso ou não estava comprometido desde a origem, a modernidade teve um âmbito de validez e sua proposta continua válida. Para eles (grupo no qual Santos coloca-se), estão colapsados os meios modernos de implementação de tal projeto. Trata-se, então, de encontrar outros meios, que não os modernos, para a implementação das promessas da Modernidade (Netto, 2000).

Porém, nos dois casos, a razão seria a principal responsável pela catástrofe que estamos vivendo no mundo contemporâneo. Existiria, segundo a crítica pós-moderna, uma tendência intrínseca, que não poderia ser eliminada, da razão como um atrofiador dos componentes emancipadores. Isto é, a razão moderna desde sua origem conduziria inevitavelmente aos malefícios que hoje enfrentamos. Resulta desta perspectiva uma entificação da razão moderna, que passa a responder por todos os males da sociedade contemporânea (Netto, 2000). Isso ocorre porque "o fundamento da ciência moderna no Ocidente (de tradição iluminista) é a racionalidade que, por sua vez, é amplamente definida como a principal característica da modernidade" (Maia, 2013, p. 8). A entificação da razão, e o direcionamento dos esforços ao seu combate, conduz apara que seja ignorada a "tessitura econômico-política e sociocultural, na qual não somente se inscreveu, mas da qual também se alimentou o projeto ilustrado", ou seja, a tessitura histórica quando da constituição do mundo burguês e a consolidação do capitalismo como modo de produção.

Netto (2000) enfatiza que o projeto da llustração é a expressão da hegemonia cultural da burguesia no ciclo da revolução burguesa e, como toda produção humana,tem um traço de classe na qual constituiu-se, mas que ela não se limita aos interesses da burguesia, não encerra ali o seu potencial emancipador. Isso significa que a burguesia, no seu período revolucionário, foi capaz de extrair os elementos emancipadores produzidos pela humanidade nos períodos anteriores, desde a Grécia. Assim, o que ocorreu, como defende Netto (ibidem), não foi uma colonização da razão pela própria razão, mas a colonização da razão por um conjunto de interesses que fizeram que a razão instrumental (de controle da natureza) se transformasse em uma lógica de subordinação social. Assim, é somente sob esta perspectiva que seremos capazes de superar a equivocada entificação da razão e compreender o desenvolvimento da razão junto ao desenvolvimento da sociedade capitalista, uma vez que não são processos identitários.

O ataque à categoria da totalidade e a demasiada ênfase nos processos locais, fluídos, efêmeros e na fragmentação da vida humana, sem que nenhuma perspectiva 
que transcenda os locais imediatos seja possível, é uma contradição, visto que o desenvolvimento econômico assume uma perspectiva cada vez mais global, os problemas tomam dimensões que transcendem indivíduos isolados. Além disso, o ataque que é deferido à razão moderna não atinge somente ela, mas qualquer forma possível de razão, o que conduz a uma nova forma de irracionalismo e um imobilismo histórico:

[...] deve parecer óbvio que a principal tendência que perpassa todos esses princípios pós-modernos é a ênfase na natureza fragmentada do mundo e do conhecimento humano, e a impossibilidade de qualquer política emancipatória baseada em algum tipo de visão "totalizante". Mesmo uma política anticapitalista é demasiado "totalizante" ou "universalizante", uma vez que dificilmente se pode dizer que exista o capitalismo como sistema totalizante, num discurso pós-moderno, de tal modo que mesmo uma crítica do capitalismo está excluída. (Wood, 1996, p. 124)

Morin, por exemplo, faz seu ataque a razão por meio da divisão disciplinar, que seria um produto da própria ciência moderna. Em "Ciência com Consciência" (Morin, 2005), ele é capaz de captar com profundidade que "[o] desenvolvimento científico comporta um certo número de traços 'negativos' que são bem conhecidos, mas que, muitas vezes, só aparecem como inconvenientes secundários ou subprodutos menores" (p. 16). Ele critica a divisão disciplinar, que "não traz unicamente as vantagens da divisão do trabalho (isto é, a contribuição das partes especializadas para a coerência de um todo organizador), mas também os inconvenientes da superespecialização: enclausuramento ou fragmentação do saber" (p. 16). Ao assumir esta perspectiva, Morin insere-se no grupo, ainda que o busque criticar, daqueles que concebem a ciência como uma instituição apartada do conjunto da sociedade, ou como ele mesmo chama "estatuto social e histórico das ciências naturais" (p. 16). Ele toma a divisão disciplinar e a fragmentação como algo inerente à própria atividade científica e não como um processo que emerge, ainda que por vias distintas, não de maneira identitária, no conjunto da sociedade. Assume ainda uma posição unilateral no que diz respeito a divisão do trabalho, concebendo-o somente pela sua suposta contribuição para a coerência do todo, não reconhecendo o caráter profundamente contraditório deste processo que, ao passo que, ao permitir a emergência de uma consciência humana cada vez mais complexa, permite, também, o surgimento de formas de trabalho cada vez mais alienadas, determinações que não estão contidas em uma outra forma específica de trabalho (seja o científico ou qualquer outra), mas decorrente do modo pelo qual a sociedade de reproduz. 


\section{Relevância: Ciência e Desenvolvimento Humano}

Os dois caminhos apresentados, que buscam fazer uma crítica ao positivismo, nos parecem falaciosos. Ambos, sob o nosso ponto de vista, não conseguem captar as profundas relações entre o desenvolvimento científico e sua corresponde apropriação pelo modo de produção capitalista. Ou seja, ambos os caminhos pelos quais muitos autores contemporâneos procuram fazer sua crítica à ciência moderna passam pelo projeto de conceber a ciência como uma instância autônoma, ou seja, como se a racionalidade moderna se desenvolvesse e se encerrasse em si mesma, à margem dos movimentos concretos de desenvolvimento humano ao longo dos últimos séculos, notadamente a partir da revolução copernicana, quando a ciência apresenta-se como uma instância revolucionária, não a única, não isolada do conjunto da sociedade, no que diz respeito às transformações sociais.

Do mesmo modo que conceber a tecnologia como mera aplicação da ciência protege a ciência de ser analisada na perspectiva de sua função social, a formulação de que a ciência é um acordo discursivo entre seus participantes, ao contrário de atacar o positivismo como concepção metodológica, protege a ciência de ser objeto de análise crítica na sua capacidade de produzir conhecimento sobre a realidade e, sobretudo, do seu papel no desenvolvimento humano, no seu potencial humanizador. A proposição de uma nova ciência, baseada em critérios discursivos intersubjetivos é a expressão contemporânea, como aponta Coutinho (2010), da decadência do pensamento burguês, processo por meio do qual a burguesia revolucionária, após a sua ascensão como classe dominante, cinde-se (no pós-1848) e tornar-se conservadora e, portanto, nega os instrumentos pelos quais puderam superar o antigo regime.

Resta-nos, então, a tarefa de problematizar a ciência a partir de seus fundamentos ontológicos, colocando na práxis humana (na unidade entre transformar o mundo, conhecer e vir-a-ser), fundante da realidade humana, o ponto de partida para uma análise das possibilidades concretas de emancipação humana por meio do conhecimento científico.

É bastante conhecida a afirmação de Marx, presente nas suas Teses sobre Feuerbach, que "[o]s filósofos apenas interpretaram o mundo de diferentes maneiras; porém, o que importa é transformá-lo(Marx \& Engels, 2011, p. 539 - itálicos no original). Como aponta Stetsenko (2008), esta afirmação deve ser tomada para além da sua dimensão epistêmica, de que os seres humanos conhecem o mundo por meio da transformação que nele operam, mas sim na perspectiva da não existência de uma separação entre transformar o mundo e conhecê-lo, nem tampouco uma separação entre transformar o mundo, conhecê-lo e ser (tornar-se) humano.

Detenhamo-nos neste ponto e aprofundemos o significado da transformação do mundo como fundamento ontológico e o coração do desenvolvimento humano. 
Tomemos, como exemplo, o trabalho de um marceneiro, que transforma a madeira para a construção de um objeto. Para que a madeira seja transformada, o marceneiro lança mão de uma série de instrumentos que já estão prontos e disponíveis para ele (formão para esculpir a madeira, por exemplo) - instrumentos que se formaram/estabilizaram ao longo da história da marcenaria e dos trabalhos artesanais, ou seja, no interior de práticas sociais nas quais desempenham uma função. Cada situação, porém, na qual tais instrumentos são utilizados é singular, único na sua totalidade: um pedaço de madeira nunca é idêntico ao outro, aquilo que um cliente encomenda não é exatamente igual ao que fez anteriormente e assim por diante. Em face desta singularidade sempre presente e não suprimível da prática concreta (e podemos extrapolar esta característica para todas as práticas humanas), toma lugar um processo (unitário) por meio do qual, primeiramente (não em ordem cronológica, ou numa sequência causal), objetiva-se os meios de ação do marceneiro: o marceneiro, apropriando-se dos instrumentos disponíveis, inicia a transformação da madeira e, portanto, testa os limites de tais instrumentos no que diz respeito a sua capacidade de responder às necessidades de transformação deste objeto singular. Na medida em que cumprem seu papel ou que precisam sofrer ajustes - por exemplo, um formão com formato específico necessitaria ser construído- a classe dos instrumentos de marcenaria/artesanato passa a cristalizar-se, ao mesmo tempo que evolui historicamente (justamente pelo fato que toda situação é ao mesmo tempo singular e genérica), ganhando existência autônoma em relação a este ato singular de transformação. Se olharmos um período histórico maior vamos perceber a maneira por meio da qual as ferramentas evoluíram e podem ser utilizadas em uma miríade de situações, que sem dúvida alguma, devem estar em maior ou menor grau em conformidade com as determinações que deram origem ao instrumento e ao seu modo específico (genérico) de atuação ${ }^{5}$.

Em segundo lugar, a realidade, após o ato de transformação realizado pelo marceneiro, é outra, está transformada. O objeto construído pelo marceneiro ganha uma existência que não é dada somente pela consciência dele, mas passa a existir na malha concreta de relações sociais: passa a fazer parte da realidade. É fundamental destacar que o trabalho do marceneiro somente é possível pela mediação da consciência. A famosa citação de Marx (2013) ${ }^{6}$ em 'O Capital', de que diferente de uma aranha que constrói com perfeição suas teias, um arquiteto, por pior que seja, já tinha na mente o resultado do seu trabalho, expressa o fato que o trabalho humano não está desvinculado de uma intencionalidade. Como aponta Leontyev (2009), o papel desempenhando pela possibilidade de superar as dicotomias da prática humana (ato de intencionalidade que

5 Isso significa que o formão é genérico na medida em que, uma vez existindo objetivamente, passa a fazer parte da totalidade do mundo, da totalidade da realidade e pode participar na transformação desta realidade.

6 "Uma aranha executa operações semelhantes às do tecelão, e uma abelha envergonha muitos arquitetos com a estrutura de sua colmeia. Porém, o que desde o início distingue o pior arquiteto da melhor abelha é o fato de que o primeiro tem a colmeia em sua mente antes de construí-la com a cera. No final do processo de trabalho, chegase a um resultado que já estava presente na representação do trabalhador no início do processo, portanto, um resultado que já existia idealmente" (Marx, 2013, p. 255-256). 
dirige as ações) é fundamental na emergência da consciência, tanto filogeneticamente (na transição para as formas humanas de sociabilidade), quanto nos atos singulares por meio dos quais a consciência individual pode emergir.

Em terceiro lugar, quanto mais executa o trabalho de marceneiro, mais ele se constitui como tal (e não como padeiro, professor ou outra profissão qualquer). Ao longo do tempo, sua sensibilidade como marceneiro vai complexificando-se, ele vai conhecendo melhor os diferentes tipos de madeiras, o modo de utilizar cada uma delas nas situações mais apropriadas: o conhecimento sobre a realidade vai tornando-se mais complexo. Ele vai se exteriorizando como tal.

É fundamental, ainda, destacar que as finalidades são sempre produzidas pelas relações sociais. A necessidade de produzir uma ferramenta específica para construir um detalhe específico em um pedaço de madeira não poderia ter existência alguma fora de um conjunto específico de relações sociais, fora de um conjunto específico de atividades. A finalidade que se manifestou no momento singular da construção da ferramenta pode desaparecer em um período maior de tempo, porém a transformação realizada por tal ferramenta objetiva-se na realidade e os meios de praticar a transformação enriquecem a subjetividade do marceneiro, assim, cristaliza-se os meios pelos quais as transformações são realizadas, ou seja, o conhecimento sobre a realidade, que não é separado da própria transformação da realidade, não são instâncias distintas, mas faces de um mesmo processo unitário de constituição da humanidade.

Ao defender o caráter ontológico da ciência, não estamos concebendo a produção científica como um reflexo mecânico da formação social na qual se insere. Tomemos o exemplo citado por Hobsbawm (2009), do caso específico da descoberta de Netuno, que se deu por um problema que emerge na Ciência e não por um conjunto de forças sociais que fizeram pressão direta para que tal descoberta ocorresse. Ou ainda, o exemplo de Kuhn (2003) acerca da invenção da garrafa de Leyden, que tem sua origem no interior de um grupo para os quais a eletricidade era um fluído e, portanto, poderia ser aprisionada. É claro que ambos os exemplos, apesar de expressarem problemáticas próprias da comunidade científica, não acontecem no vazio. Ao emergirem em um determinado momento histórico, expressam em maior ou menor grau o estágio do desenvolvimento científico de uma parcela da sociedade, porém a dinâmica do desenvolvimento científico e do desenvolvimento social não podem ser reduzidas uma a outra.

Tomar a práxis como fundante da realidade humana e, consequentemente, do complexo social que origina a Ciência, nos traz, antes de mais nada, a tarefa de olhar esta problemática sob uma perspectiva histórica (genética). Desde a emergência do trabalho, do ser social e da linguagem humana, o conhecimento ${ }^{7}$ acerca da realidade

7 Toda práxis está diretamente orientada para a consecução de uma finalidade concreta determinada. Para tanto, deve ser conhecida a verdadeira constituição dos objetos que servem de meio para tal posição de finalidade, pertencendo à dita constituição também as relações, as possíveis consequências etc. Por isso a práxis está inseparavelmente ligada ao conhecimento; por isso o trabalho é, conforme procuraremos mostrar, a fonte originária, o modelo geral, também da atividade teórica humana. (Lukács, 2012, p. 40) 
já estava presente no modo por meio do qual a humanidade passou a reproduzirse, generalizando a experiência cotidiana e criando a possibilidade de que os meios humanos de ação/transformação da realidade (e transformação da própria individualidade humana) fossem acumulados e transmitidos ao longo das gerações, tornando-se cada vez mais complexos (Lessa, 2001). Com a emergência do trabalho, os seres humanos são confrontados com a dimensão objetiva da realidade sobre a qual os seus atos teleológicos são dirigidos. A fim de que estes atos, projetos idealizados na consciência, fossem efetivados, torna-se fundamental algum conhecimento sobre a objetividade da realidade, conhecimento que a cada novo ato de trabalho é continuamente confrontado, testado e generalizado. Assim, a práxis "dá origem a uma série de complexos sociais que têm a função social de sistematizar os conhecimentos adquiridos em uma concepção de mundo que termine por fornecer, no limite, uma razão para a existência humana".

A ciência, a religião, as artes, a filosofia etc. têm assim suas origens nestes complexos sociais que emergem a partir das generalizações da prática cotidiana da humanidade no seu constante enfrentamento com a realidade. "O desenvolvimento da sociabilidade possibilitou e exigiu que a ciência se desenvolvesse em um complexo social específico, altamente especializado e sofisticado, e que apenas mediadamente se relaciona à transformação da natureza [...]" (Lessa, 2012, p. 24). A relativa autonomia que cada forma de atividade ganha é um fenômeno posterior, que vem com as formas mais complexas de transformação da realidade pelos seres humanos e acumulações cada vez mais complexas de objetivações. Kuhn (2003) bem aponta que no início nenhuma ciência podia ser interpretada a partir de um corpo implícito de crenças, metodologias e teorias bem definidas.

O trabalho, apesar de ser orientado para um ato singular, é impelido a todo momento a transcender esta singularidade. A necessidade de desenvolver conhecimento verdadeiro acerca da realidade, a fim de que a transformação possa ocorrer, faz com o que os conhecimentos produzidos não estejam limitados somente a uma situação particular, mas que tenham validade para uma classe maior de situações. Esse processo é o que Lukács (2012), utilizando-se da terminologia de Hartman, chama de intentio recta, por meio do qual, na prática cotidiana da humanidade, se impõe a necessidade de conhecimentos verdadeiros para a efetivação do trabalho.

Atentemo-nos, porém, a desenvolver aquilo que anteriormente chamamos de conhecimento sobre a objetividade da realidade, aquele conhecimento que é indispensável para a efetivação daquela teleologia que orienta o processo de trabalho humano. Imagine que o marceneiro, do nosso exemplo anterior, quisesse agora transformar um pedaço de madeira em um bloco de ouro, quais seriam as possibilidades para que isso ocorresse? Ele teria sucesso nesta empreitada? Resposta a esta pergunta não pode ser dada de maneira simplista. É claro que a Física, Química ou as Engenharias, no seu estágio atual de desenvolvimento, não conhecem nenhum 
processo por meio do qual esta transformação seja possível, mas esta afirmação não pode ser tomada de forma unilateral, atribuindo as limitações desta transformação a uma possível "natureza em-si", fixa na sua existência. Se na Antiguidade algum indivíduo fosse questionado sobre a possibilidade dos seres humanos voarem, a resposta poderia ser negativa, atribuindo a impossibilidade deste feito às condições biológicas dos seres humanos - não possuírem asas como os pássaros, por exemplo. A história nos mostra, porém, que o desenvolvimento das atividades humanas, do estabelecimento de novas relações com a totalidade do mundo, o voo humano passa a ser possível.

O que queremos com estes exemplos é superar a concepção das coisas como objetos isolados, dotados de propriedades intrínsecas, rumo a uma concepção das coisas como processos. O que seriam os átomos senão a totalidade das relações que são estabelecidas em torno deles (e sintetizadas por meio deles) e o conhecimento sobre átomos senão as apropriações do conjunto das determinações concretas que os constituem como tal e das possibilidades de operar com eles na transformação da realidade? Cada vez que o átomo (como uma totalidade de relações) é "utilizado", que alguma transformação do mundo é operada por meio dele, ele é posto à prova na sua relação com a totalidade do existente e, portanto, transforma-se, evolui, assim como o modo dos seres humanos com ele operar também se transforma ao longo da história - desde o átomo de Demócrito, por exemplo, às complexas experimentações realizadas pelo $\mathrm{LHC}^{8}$. Assim, a possibilidade de transformar madeira em ouro não está simplesmente em conhecer o suposto conjunto de mecanismos isolados, mas o papel que possuem dentro das relações dos processos de transformação operados pelos humanos, no interior das diversas forças produtivas situadas historicamente. Ou seja, não é possível afirmar que jamais madeira poderá ser transformada em ouro, mas que no atual desenvolvimento histórico da ciência, tecnologia e indústria esse processo não é possível de ser realizado, ou seja, estas são as determinações concretas que constituem as coisas no interior da totalidade. Assim, o marceneiro, tendo este conhecimento da objetividade (da totalidade das relações) do processo que deseja realizar, saberá que seu ato de transformação não será possível dadas as condições de transformação hoje operadas pela humanidade, mas que isto não é dado para todo o sempre de maneira imutável'.

Porém, é também verdade que esses conhecimentos necessários para a efetivação do trabalho não vêm de forma isolada. Eles vêm associados a outros conhecimentos, concepções místicas, visões de mundo, que fazem que no processo de efetivação do

8 Kuhn (2003) traz um exemplo interessante, acerca da "descoberta" do oxigênio, que passa a existir de diferentes maneiras em diferentes contextos, de maneira que não se pode falar de um único oxigênio ou caracterizar a sua descoberta a partir de um único evento. Daí a necessidade de compreender oxigênio como processo e não como um coisa-em-si estática e imutável.

9 É claro que o feito do nosso exemplo, da transformação de madeira em ouro, pode não vir nunca a ocorrer, o que não invalida o argumento que desenvolvemos aqui. Uma infinidade de outros exemplos poderia ser utilizada: desde o já citado exemplo da possibilidade dos seres humanos voarem até a produção de energia por meio da fissão nuclear, passando por uma série de possibilidades de transformações operadas na vida cotidiana da humanidade. 
trabalho, além dos conhecimentos necessários para a efetivação de um ato concreto de trabalho, sejam generalizados com ele um conjunto de outros conhecimentos acerca da realidade. E estes podem vir a constituir-se como imagens místicas acerca do mundo, visões religiosas e, sobretudo, uma concepção antromorfizadora da realidade, segundo a qual o mundo passa a ganhar qualidades humanas.

Este é o processo que Lukács (2012) (citando Hartmann), denomina intentio obliqua. Portanto, torna-se fundamental ressaltar que não há uma relação mecânica ou unívoca entre desenvolvimento científico e a transformação das concepções de mundo ou ampliação da consciência humana rumo a ontologias menos místicas ou fictícias. Lukács aponta que "em culturas como a indiana, por exemplo, foi possível um desdobramento relativamente elevado da matemática, sem que esta pudesse exercer nenhuma influência sobre os limites da concepção de mundo, traçados exclusivamente pela teologia" (Lukács, 2012, p. 24).

Ele destaca, ainda, que no início do desenvolvimento das ciências, as generalizações foram obrigadas a adaptar-se a concepções de mundo mágicas e religiosas de cada momento histórico: "operações matemáticas relativamente bastante desenvolvidas e observações astronômicas relativamente precisas foram postas a serviço da astrologia" (Lukács, 2013, p. 109). Também os desenvolvimentos científicos dos períodos anteriores ao de Galileu e Copérnico foram incorporados facilmente pela ontologia religiosa vigente, considerando a doutrina da dupla verdade, cujos fundamentos permitia a existência de uma verdade de razão, que se poderia extrair das obras de Aristóteles, o filósofo por excelência, e de uma verdade de fé. A teoria da dupla verdade que emerge no período de Galileu é geralmente atribuída ao cardeal Belarmino, e é representada por Brecht (1991, p. 111): "Vamos marchar com os tempos, Barberini. Se os mapas celestes, que dependem de uma hipótese nova, facilitam a vida de nossos navegantes, eles que usem os mapas. O que nos desagrada são doutrinas que tomam errada a Escritura". Para Lukács, essa necessária conformação das generalizações aos princípios religiosos/místicos gera um dualismo entre a racionalidade do trabalho e a aplicação dos conhecimentos a fim de conhecer o mundo, que só entraria em crise profunda nos tempos de Copérnico, Kepler e Galileu.

É neste sentido que Feyerabend defende que o "copernicanismo - teoria copernicana - e outros ingredientes essenciais da ciência moderna sobreviveram apenas porque, em seu passado, a razão foi frequentemente posta de lado" (Feyerabend, 2011, p. 145). Sob o nosso ponto de vista, quando Feyerabend aponta que os cientistas foram obrigados a abandonar a razão, isto se refere ao abandono dos métodos que são tipicamente associados ao trabalho dos cientistas e não ao abandono de qualquer razão ${ }^{10}$ ou de qualquer recurso intelectivo fundamental para a investigação científica. Feyerabend (2011) já bem demonstrou que durante o processo cognitivo os cientistas lançam mão

10 Não estamos também tomando aqui "razão" de forma abstrata e ahistórica ou nos referindo a possibilidade de uma única razão. Estamos, porém, nos referimos à possibilidade concreta de que a realidade seja apreendida e transformada de maneira consciente pela humanidade. 
de uma gama quase infinita de recursos metodológicos, como concepções místicas, ideias oriundas de outras áreas do conhecimento.

A necessidade de adaptar-se não acontece somente na relação da ciência com as visões de mundo mais amplas, mas também dentro da própria ciência, como bem aponta Kuhn (2003), por meio do conceito de paradigma. O paradigma, segundo ele, é capaz de restringir a visão dos cientistas, que devem buscar fazer com que a natureza e os problemas que enfrentam sejam encaixados dentro de um conjunto pré-estabelecido de regras e teorias, mas que esta limitação é uma condição necessária para o seu desenvolvimento.

De que maneira, então, a ciência, mesmo desenvolvendo-se com relativa autonomia da prática social ou muitas vezes subordinando-se a visões de mundo fantasiosas pode ajudar a romper com tais visões nas quais se insere? Como foi possível a ciência desempenhar um papel tão importante na transformação da concepção medieval de mundo a partir da revolução Copérnico-Galileana ou contribuir para abalar as estruturas do espaço-tempo no começo do século XX?

É evidente que a Ciência, como toda objetivação humana, é situada e profundamente datada (Bernal, 1965). Como complexo social, carrega consigo as marcas do grupo no qual emerge e quais visões de mundo e projetos de sociedade ajuda a sustentar, ainda que o faça de maneira implícita. É uma síntese de determinados meios de transformação e apropriação da realidade que emergem num dado momento histórico. Daí a concepção de ciência manifestada por Bernal: "A caracterização daquilo que é ciência não pode ser feito sem a profunda caracterização do momento histórico e das relações sociais nas quais se quer caracterizar ciência" (Bernal, 1965, p. 31 - tradução nossa).

Ao discutir o caráter ontológico da Ciência, procuramos mostrar que ela tem sua origem (seu fundamento) na práxis humana, e que, justamente, por estar fundada no trabalho, remete, necessariamente, para além dos atos singulares de transformação da realidade, alcançando dimensões genéricas. Ou seja, o conjunto dos atos singulares de transformação passa a existir como uma síntese capaz de expressar a totalidade das transformações operadas na realidade postas continuamente à prova pela práxis humana.

Em momentos específicos, a Ciência alcança dimensões tão genéricas que coloca em questão as estruturas da ordem vigente e os pressupostos sobre os quais a transformação da realidade pelo conjunto dos humanos é concebida - atinge questões de natureza ontológica: modelo heliocêntrico, a introdução de um princípio histórico no desenvolvimento dos seres vivos, no desenvolvimento da Terra e também no desenvolvimento do Universo, a natureza do espaço-tempo. $E$ à medida que as novas visões científicas estão em ressonância com as transformações que passam na totalidade da sociedade, uma revolução nas visões de mundo toma lugar. A Igreja, por exemplo, conseguiu fazer com que Galileu se retratasse acerca das suas 
ideias, "mas não pôde deter a marcha triunfal da ontologia terrenalmente orientada, cientificamente fundada; essa ontologia minou totalmente, de modo irrecuperável, a ontologia bíblico-cristã" (Lukács, 2012, p. 125). Não significa, no entanto, que Galileu por si só conseguiu minar a antiga Ontologia. Ao contrário, Galileu é a síntese das ideias científicas revolucionárias do seu momento histórico e ele consegue expressar, no plano científico, nas objetivações científicas, o movimento de transição pelo qual a humanidade estava passando. Movimento que também é expresso por outros indivíduos por meio de outras objetivações: arte, filosofia, música etc. Isto não significa que o papel de Galileu é simplesmente passivo neste processo, como se fosse um indivíduo puramente determinado pelas relações sociais nas quais estava imerso e que uma revolução científica de tal ordem pudesse ocorrer sem que tal síntese fosse por ele operada. Galileu é, por outro lado, um indivíduo humanamente rico. Koyré (1982) bem observa que:

o telescópio de Galileu não é um simples aperfeiçoamento da luneta 'batava', é construído a partir de uma teoria ótica, e é construído com uma determinada finalidade científica, a saber, revelar a nossos olhos coisas que são invisíveis a olho nu. (ibidem, p. 55).

Assim, a riqueza intelectual de Galileu desempenha um papel fundamental nos meios pelos quais a sua investigação científica é conduzida. Galileu, à medida que é síntese das relações sociais mais elevadas do seu tempo, somente o é por apropriar-se das objetivações como a matemática, filosofia, arte, fazendo com que se constitua de um "cientista" intelectivamente rico.

\section{Conclusão}

Considerando o conjunto das discussões que travamos até aqui e os elementos analíticos que conseguimos sintetizar, a nossa conclusão tomará um caráter de agenda de problemas a serem enfrentados. São eles: a necessária superação do modelo de Ciência neutra e do determinismo tecnológico; a necessária socialização dos meios de produção científicos, e a necessária mediação concreta entre a sociedade e a ciência por meio da Educação em Ciências.

A necessidade de superar o "mito da ciência neutra" e o "mito do determinismo tecnológico" (Auler, 2002) é um projeto tanto dos filósofos da ciência quanto dos pesquisadores do campo da educação em ciências, sobretudo dos estudos CTS. Uma importante contribuição para a superação da concepção da Ciência neutra é feita por Lukács (2012). Em vez de concebê-la como "falsa consciência", como uma instância falsificadora da realidade, ele a trata como desempenhando uma função social na resolução de conflitos da vida cotidiana da humanidade. Ao assim proceder, 
ele é capaz de superar a dualidade entre falsa consciência e Ciência, retirando, assim, desta última a (falsa) responsabilidade de eliminar a primeira (e consequentemente as ideologias) e desempenhar o papel de intervir nas questões éticas. Considerando o trabalho como fundamento de ambas, Ciência e Tecnologia, a discussão desloca-se para a função social que desempenham na sociedade de classes e não no suposto fundamento universal da ciência de se opor a qualquer forma de falsificação da realidade.

Além disso, nunca é demais lembrar que a história tem mostrado muitos exemplos nos quais uma "falsa" teoria científica, ou uma teoria que num período histórico posterior foi superada pela própria comunidade científica, é capaz de trazer resultados importantes: o sistema ptolomaico e a possibilidade das navegações, o modelo atômico de Bohr e o espectro de radiação, o espaço e o tempo fixos de Newton e a mecânica.

Colocar a ciência nos seus fundamentos ontológicos nos permite deslocarmos para além da discussão entre ciência e pseudociência ou ciência e ideologia em direção aos papeis desempenhados por cada forma de objetivação na reprodução da sociedade tendo como pano de fundo a necessidade uma radical mudança na estrutura da sociedade.

O lugar que a Ciência, ou qualquer forma relativamente autônoma de atividade humana, ocupa na totalidade da sociedade assume formas bastante diferenciadas, postas pelos problemas histórico-sociais concretos de cada época. Neste sentido, uma forma específica de objetivação não contém em-si a capacidade de desempenhar um papel humanizador ou desumanizador, isso somente se dá pelas relações que estabelece com a cadeia de relações estabelecidas historicamente, sua função social. Tomemos, por exemplo, a teoria de Darwin, que em um momento histórico serviu para introduzir na natureza um princípio historicizador, ampliando as possibilidades de compreensão da realidade pelos seres humanos, enquanto esta mesma teoria, em outro momento histórico, foi utilizada para justificar concepções fascistas de sociedade. Isso explicita, em grande medida, a impossibilidade de conceber uma objetivação humana apartada da totalidade concreta na qual se efetiva como transformadora da realidade.

É, então, no interior deste processo contraditório que a análise das relações entre Ciência e desenvolvimento humano deve ser posta. As possibilidades reais de emancipação por meio da Ciência estão associadas à sua capacidade de transcender as questões puramente pragmáticas, imediatas, e lançar-se rumo a questões de natureza ontológica, colocando de forma problemática a estrutura da realidade. Porém, justamente por ser um processo contraditório, à medida que emergem possibilidades de emancipação, a negação dessa potencialidade emancipadora é também uma possibilidade, sobretudo quando a Ciência é apropriada por um grupo social cujo interesse é a manutenção do status quo ou das relações de opressão. Assim, uma tarefa histórica que nos é posta é a da socialização da Ciência, tomada aqui na sua totalidade e 
não somente dos seus produtos e resultados na forma de conhecimentos cristalizados, mas também dos processos por meio dos quais a Ciência é produzida, o que implica o necessário posicionamento político diante da agenda científica de maneira a expressar os interesses concretos de uma sociedade em vias de emancipação.

Esta perspectiva é capaz de tornar explícito o caráter político não somente da atividade educacional, mas também da atividade de pesquisa (em Educação de Ciências, neste caso em particular), que, neste momento histórico, tem a possibilidade de assumir o papel de mediadora entre a sociedade e a atividade científica institucionalizada. Possibilidade que se realiza àmedida que assume, inclusive e efetivamente, o seu papel de criticar os processos de produção científica e de ser portadora dos anseios emancipadores da sociedade, superando a posição unilateral de simples transmissora/ tradutora/reprodutora de conhecimentos produzidos numa esfera outra, distinta da vida cotidiana.

\section{Referências}

Adorno, T. W. (2003). Notas de Literatura I. São Paulo: Editora 34.

Aikenhead, G. S. (1994). The Social Contract of Science. In J. Solomon \& G. Aikenhead (Eds.), STS Education, International Perspectives (pp. 11-20). New York and London: Teachers College Press.

Aikenhead, G. S. (2006). Science education for everyday life: evidence-based practice. New York and London: Teachers College Press.

Auler, D. (2002). Interações entre Ciência-Tecnologia-Sociedade no contexto de formação de professores de ciências. Universidade Federal de Santa Catarina.

Auler, D. (2011). Novos caminhos para a educação CTS: ampliando a participação. In Wildson Luiz Pereira dos Santos \& D. Auler (Eds.), CTS e educação científica: desafios, tendências e resultados de pesquisa (pp. 73-97). Brasília.

Auler, D., \&Delizoicov, D. (2001). Alfabetização científico-tecnológica para quê? ENSAIO - Pesquisa Em Educação Em Ciências, 03(1), 1-17.

Auler, D., \& Delizoicov, D. (2015). Investigação de temas CTS no contexto do pensamento latino-americano. Linhas Críticas, 21(45), 275-296.

Bagdonas, A., \& Azevedo, H. L. (2017). O projeto de lei "Escola sem Partido" e o Ensino de Ciências. Alexandria: Revista de Educação Em Ciência e Tecnologia, 10(2), 259. https://doi.org/10.5007/1982-5153.2017v10n2p259 
Bernal, J. D. (1965).Science in History.Vol 1. C. A. Watts \& Co Ltd.

Brecht, B. (1991). Teatro Completo, 6. Rio de Janeiro: Paz e Terra.

Cachapuz, A., Praia, J.,\& Jorge, M. (2004). Da educação em ciência às orientações para o ensino das ciências: um repensar epistemológico. Ciência \& Educação (Bauru), 10(3), 363-381. https://doi.org/10.1590/S1516-73132004000300005

Camillo, J. (2015, September 15). Contribuições iniciais para uma filosofia da educação em ciências. Universidade de São Paulo, São Paulo. https://doi. org/10.11606/T.81.2015.tde-25112015-144311

Cassab, M. (2008). A Democracia como balizadora do Ensino das Ciências na Escola: Como discutir este desafio? Revista Brasileira de Pesquisa Em Educação Em Ciências, 8(2).

Coutinho, C. N. (2002). A democracia na batalha das ideias e nas lutas políticas do Brasil de hoje. In O. Fávero \& G. Semeraro (Eds.), Democracia e construção do público no pensamento educacional brasileiro (pp. 11-39). Petrópolis: Vozes.

Coutinho, C. N. (2010). O Estruturalismo e a Miséria da Razão (2a). São Paulo: Expressão Popular.

DeBoer, G. E. (1991). A History of Ideas in Science Education: Implications for Practice. New York and London: Teachers College Press.

DeBoer, G. E. (2000). Scientific literacy: Another look at its historical and contemporary meanings and its relationship to science education reform. Journal of Research in Science Teaching, 37(6), 582-601. https://doi.org/10.1002/10982736(200008)37:6<582::AID-TEA5>3.0.CO;2-L

Donnelly, J. F. (2002). The "humanist" critique of the place of science in the curriculum in the nineteenth century, and its continuing legacy. History of Education, 31(6), 535-555. https://doi.org/10.1080/00467600210167073

Eagleton, T. (1998). As llusões do Pós-Modernismo. Rio de Janeiro: Jorge Zahar.

Fensham, P. J. (2015). Connoisseurs of Science: A Next Goal for Science Education? In D. Corrigan, C. Buntting, J. Dillon, A. Jones, \& R. Gunstone (Eds.), The Future in Learning Science: What's in it for the Learner? (pp. 35-59). Cham: Springer International Publishing. https://doi.org/10.1007/978-3-319-16543-1_3

Feyerabend, P. (2011). Contra o Método (2nd ed.). São Paulo: Editora da Unesp.

Gouw, A. M. S., Mota, H. S., \& Bizzo, N. M. V. (2016). O Jovem Brasileiro e a Ciência: Possíveis Relações de Interesse. Revista Brasileira de Pesquisa Em Educação Em 
Ciências, 16(3), 627-648.

Hansson, S. O. (2017). Science denial as a form of pseudoscience.Studies in History and Philosophy of Science Part A, 63, 39-47. https://doi.org/10.1016/j. shpsa.2017.05.002

Hobsbawm, E. (2009). A era das revoluções: Europa 1789-1848. Rio de Janeiro: Paz e Terra.

Kuhn, T. S. (2003). A estrutura das revoluções científicas. São Paulo: Perspectiva.

Laugksch, R. C. (2000). Scientific literacy: A conceptual overview. Science Education, 84(1), 71-94. https://doi.org/10.1002/(SICI)1098-237X(200001)84:1<71::AIDSCE6>3.0.CO;2-C

Leontyev, A. N. (2009). The Development of Mind. Marxists Internet Archive.

Lessa, S. (2001).Lukács e a Ontologia: uma introdução. Outubro (São Paulo), 5(1).

Lessa, S. (2012). Para compreender a Ontologia de Lukács (3ª). Ijuí: Editora Unijuí.

Levinson, R. (2010). Science education and democratic participation: an uneasy congruence? Studies in Science Education, 46(1), 69-119. https://doi. org/10.1080/03057260903562433

Lukács, G. (2012). Para uma ontologia do ser social I. São Paulo: Boitempo.

Lukács, G. (2013). Para uma ontologia do ser social II. São Paulo: Boitempo.

Maia, E. L. C. (2013). Pós-modernos, marxistas e a pobre ciência na modernidade. Pensamento Plural, (13), 7-27.

Marx, K. (2013). O capital: crítica da economia política: Livro I: o processo de produção do capital. São Paulo: Boitempo.

Marx, K., \& Engels, F. (2011). A ideologia alemã: Crítica da mais recente filosofia alemã em seus representantes Feuerbach, B. Bauer e Stirner, e do socialismo alemão em seus diferentes profetas. São Paulo: Boitempo.

Merton, R. K. (1970). Science, technology and society in seventeenth century England. New York: Howard Fertig.

Millar, R. (2006). Twenty First Century Science: Insights from the design and implementation of a scientific literacy approach in school science. International Journal of Science Education, 28(13), 1499-1521. https://doi. org/10.1080/09500690600718344 
Morin, E. (2005). Ciência com consciência. Bertrand Brasil.

Netto, J. P. (2000). Modernidade e Pós-Modernidade. Retrieved from https://www. youtube.com/watch?v=fHrZi1F7jd4

Nicioli, R. B., \& Cri. (2012). História e Memória do Ensino de Física no Brasil: A Faculdade de Medicina de São Paulo (1913-1943), 18(4), 851-873.

Nielsen, J. A. (2012). Co-opting Science: A preliminary study of how students invoke science in value-laden discussions.International Journal of Science Education, 34(2), 275-299. https://doi.org/10.1080/09500693.2011.572305

Osborne, J. (2007). Science education for the twenty first century.Eurasia Journal of Mathematics, Science and Technology Education, 3(3), 173-184. https://doi. org/10.1080/13586840903194748

Osborne, J. (2010). Science for citizenship. In J. Osborne \& J. Dillon (Eds.), Good Practice in Science Teaching: What research has to say (Second Edi).Maidenhead: Open University Press.

Pérez, D. G., Montoro, I. F., Alís, J. C., Cachapuz, A., \& Praia, J. (2001). Para uma imagem não deformada do trabalho científico. Ciência \& Educação (Bauru), 7(2), 125-153. https://doi.org/10.1590/S1516-73132001000200001

Praia, J., Gil-Pérez, D., \& Vilches, A. (2007). O papel da natureza da ciência na educação para a cidadania. Ciência \& Educação (Bauru), 13(2), 141-156. https://doi. org/10.1590/S1516-73132007000200001

Rodrigues, A., Camillo, J.,\& Mattos, C. (2014). Quasi-appropriation of dialectical materialism: a critical reading of Marxism in Vygotskian approaches to cultural studies in science education. Cultural Studies of Science Education, 9(3), 583-589. https://doi.org/10.1007/s11422-014-9570-7

Santos, B. S. (n.d.). Introdução a uma ciência pós-moderna. Retrieved from http:// www.boaventuradesousasantos.pt/pages/pt/livros/introducao-a-uma-cienciapos-moderna.php

Santos, B. S. (1997). Pela mão de Alice: O social e o político na transição pós-moderna. São Paulo: Cortez.

Sasseron, L. H. (2015). Alfabetização Científica, Ensino Por Investigação E Argumentação: Relações Entre Ciências Da Natureza E Escola. Ensaio Pesquisa Em Educação Em Ciências (Belo Horizonte), 17(spe), 49-67. https://doi. org/10.1590/1983-2117201517s04 
Sasseron, L. H., \& Carvalho, A. M. P. de. (2011). Alfabetização científica: uma revisão bibliográfica. Investigações Em Ensino de Ciências, 16(1), 59-77.

Schulz, R. M. (2009). Reforming Science Education: Part I. The Search for a Philosophy of Science Education.Science \& Education, 18(3-4), 225-249. https:// doi.org/10.1007/s11191-008-9167-1

Shamos, M. H. (1995). The myth of scientific literacy. New Brunswick, New Jersey: Rutgers University Press. https://doi.org/10.1063/1.2807544

Shinn, T., \& Ragouet, P. (2008). Controvérsias sobre a ciência: por uma sociologia transversalista da atividade científica. São Paulo: Editora 34. Retrieved from https:// books.google.com.br/books?id=dKGIPgAACAAJ

Sjøberg, S. (2017). PISA as a Challenge for Science Education: Inherent Problems and Problematic Results from a Global Assessment Regime. Revista Brasileira de Pesquisa Em Educação Em Ciências, 17(1), 327-363.

Stetsenko, A. (2008). From relational ontology to transformative activist stance on development and learning: expanding Vygotsky's (CHAT) project. Cultural Studies of Science Education, 3(2), 471-491. https://doi.org/10.1007/s11422-008-9111-3

Wood, E. M. (1996). Em defesa da História: o Marxismo e a Agenda Pós- Moderna. Crítica Marxista, 1(3), 118-127.

Yang, F. Y. (2004).Exploring high school students' use of theory and evidence in an everyday context: The role of scientific thinking in environmental science decisionmaking.International Journal of Science Education, 26(11), 1345-1364. https://doi. org/10.1080/0950069042000205404

Yang, F. Y., \& Anderson, O. R. (2003).Senior high school student's preference and reasoning modes about nuclear energy use.International Journal of Science Education, 25(2), 221-244. https://doi.org/10.1080/09500690210126739 
Juliano Camillo Possui Doutorado em Ensino de Ciências - Física, pelo Programa Interunidades em Ensino de Ciências da Universidade de São Paulo.Atualmente é Professor do Departamento de Metodologia de Ensino, do Centro de Ciências da Educação, e do Programa de Pós Graduação em Educação Científica e Tecnológica, da Universidade Federal de Santa Catarina. É membro do Grupo de Pesquisa ECCo, da Universidade de São Paulo e líder do Grupo de Pesquisa CEUCl, da Universidade Federal de Santa Catarina.

Cristiano Mattos Possui Doutorado em Física pelo Instituto de Física da Universidade de São Paulo. Atualmente é professor do Departamento de Física Experimental do Instituto de Física, e do Programa Interunidades em Ensino de Ciências, da Universidade de São Paulo. Atua na área de Ensino de Física. É líder do Grupo de Pesquisa ECCo. 